\title{
Application of genetic algorithm for crack diagnosis of a free-free aluminum beam with transverse crack subjected to axial and bending load
}

\author{
Sanjay K. Behera ${ }^{1 *}$, Dayal R. Parhi ${ }^{2}$,Harish C. Das ${ }^{3}$ \\ ${ }^{1}$ Institute of Technical Education and Research, Siksha 'O' Anusandhan Deemed to be University, \\ Bhubaneswar, Odisha, India-751030 \\ Phone: +91-8763173320 \\ ${ }^{2}$ Department of Mechanical Engineering, National Institute of Technology, Rourkela, Odisha, India \\ 769008,dayalparhi@yahoo.com \\ ${ }^{3}$ Mechanical Engineering Department, National Institute of Technology, Shillong, Meghalaya, \\ India-793003 \\ * Email: sanjaybeheraoec@gmail.com
}

\begin{abstract}
A beam structure in presence of crack subjected to both bending and axial load has been investigated for damage diagnosis to predict crack location and crack depth based on an optimized intelligent technique using genetic algorithms approach. Numerical with experimental investigations have been conducted in a free-free beam model to calculate natural frequencies. In this work, genetic algorithm as an optimized artificial intelligent technique has been used which employs first three relative modal parameters like natural frequencies as input data taken from numerical and experimental results to obtain optimized crack locations and crack depths as output parameters. This methodology has been found to be quite reliable for fault diagnosis by monitoring the possible variations in the relative natural frequencies of a free-free beam element in presence of crack. This paper also gives an insight into the deviation of the results of the proposed methodology from the experimental result.
\end{abstract}

Keywords: Crack; natural frequency; mode shapes; numerical analysis; genetic algorithm.

\section{INTRODUCTION}

Presence of crack in engineering structures is the most critical fault and its accurate detection and proper diagnosis at early stage has been a challenging work for researchers. In the present work, genetic algorithm as an artificial intelligence technique has been established as an effective methodology for crack detection and diagnosis. Genetic algorithm technique is a computational methodology adopting the concepts of Darwin's theory of natural evolution. It choses few good number of solutions from available solution which is subjected to crossover and mutation as a part of reproduction process. The output solution is expected to be better and improved as compared to the previous solutions. This process has attracted many researchers because of its operational simplicity and accuracy. Present study suggests a novel genetic algorithm technique for crack diagnosis in a free-free aluminum beam with a transverse crack. The relative changes in vibration parameters due to the presence of crack are the basis for crack diagnosis in a cracked beam structure. An initial data pool that constitutes different vibration characteristics is created using the result of numerical and theoretical analysis. In this study, the mode shapes of experimental and numerical analysis are compared as an evidence of correctness of numerical procedure. 
First three relative natural frequencies (usually lower natural frequencies) obtained from experimental analysis are considered as input parameters to the proposed GA model. The two output parameters obtained from GA technique are relative crack location and relative crack depth which are then compared with the corresponding experimental results and the deviation in the results is presented. This methodology performs under the survival of the fittest principle by refining a set of solution in an iterative manner. This intelligent technique is a population based ecology inspired evolutionary algorithm which uses elements from search space in the form of binary strings. Genetic algorithm works on digital platform based selection procedure using biological mechanism. Generalizing the statement, it selects the biological species that have adopted, survived and flourished in a highly competitive environment, based on the fundamental principle of survival of the fittest concept.

He et al. [1] have developed a model that uses genetic algorithm concept to detect a crack on a shaft and optimized it using finite element method and have applied the model for outputs as solutions. Halo and Xia [2] have used a real number encoding system in the genetic algorithm for detection of crack in the damaged structures and compared the changes in measurements using minimized objective function. Krawczuk [3] have developed a working crack model identification using the combined model of genetic algorithm, gradient technique and wave propagation in a beam structure. He and Hwang [4] have used the combination of adaptive genetic algorithm based real parameter model with simulation based annealing technique to develop a suitable and effective algorithm for crack detection in a damaged beam structure. Perera and Torres [5] have formulated a non-classical optimisation procedure using genetic algorithm and have proposed the methodology to identify damaged area in the damaged structural beam. Chen et al. [6] have developed an optimized procedure in a vibration based model using genetic algorithm by positioning the piezoelectric sensor for crack identification in a wing composite box. They have used HilbertHuang transform to detect crack in large structure. Panigrahi et al. [7] have presented a paper on microscopic structural damage identification by formulating genetic algorithm based objective function. Vakil-Baghmisheh et al. [8] have formulated a procedural technique for fault diagnosis using binary and continuous genetic algorithm in a damaged crack model by minimising the parameters based on the variation in the experimental and theoretically estimated natural frequencies. Saridakis et al. [9] have studied the coupling effect in a bending vibration of a cracked shaft and introduced a technique to identify rotational angle of crack and evaluated crack characteristics by selecting and minimising effective objective function. Meruane and Heylen [10] have introduced a damage penalization factor to eliminate false damage detection in presence of machine operational noise using a real coded hybrid genetic algorithm program for damage diagnosis of dynamically vibrating structure. Nobahari and Seyedpoor [11] have developed an effective and successful optimization technique using genetic algorithm in a dynamically vibrating structure with multiple damage based on evaluated natural frequency using finite element analysis. They have compared their result with two bench mark test results as a mark of computational robustness of their proposed methodology. Buezas et al. [12] have studied a genetic algorithm based optimized methodology to deal with the crack detection in dynamically vibrating structures by introducing a novel concept based on the approach of the crack interface contact. They have used experimental data as input parameters to the adopted procedure for crack diagnosis of the damaged vibrating structures. The benefits of procedure for automated damage identification and diagnosis is low maintenance and repair cost. Zhang and Randall [13] have presented a combined application of kurtogram and genetic algorithm for fault diagnosis of roller element bearing. Vibration signals are initially captured using fast kurtogram and final optimization is made using genetic algorithm. The results of combined applications are quite encouraging over other optimal procedure for resonant demodulation. Parhi et al. [14-17] have used various techniques for fault diagnosis of cracked structures. Perera et al. [18] have established a genetic algorithm program based on the solution of 
multi objective optimization for crack detection and diagnosis. They have compared aggregating function based GA optimization.

Friswell et al. [19] have presented a methodology combining Eigen sensitivity method with Genetic algorithm for identification of crack positions in a dynamically vibrating beam structures. Xiang et al. [20] have modelled the damaged shaft using wavelet based technique to obtain precise modal parameter like natural frequencies. They used first three relative natural frequencies to locate the crack and used genetic algorithm to detect the extent of damage in the cracked shaft. They have presented a novel methodology for identifying crack position and estimate crack intensity in a rotating beam. Zhang et al. [21] have introduced a genetic algorithm based programming to detect faults in rotating machine. The result obtained is suggested to be better or match with the performance obtained through other technique like ANN or support vector machines. Singh et al. [22] have developed a genetic algorithm based technique utilizing transversely applied induced force to the shaft rotating at various frequencies of a harmonically excited vibration unit to identify and locate multi cracks and the depth of cracks in two stages of testing process. Nguyen et al. [23] have designed a technique using Genetic Algorithm and Adaptive Network based Fuzzy Inference System (ANFIS) for fault detection and diagnosis using the parameters governing system conditions of vibration analysis. They have tested the proposed model successfully with accuracy. Parhi et al. [24-29] have analyzed AI techniques for solving various engineering problems. Pawar et al. [30] have used fuzzy and genetic algorithm based on line damage monitoring hybrid technique for composite rotor blade. They have used the deviations in force and displacement measurements to formulate the rules for fuzzy system and developed a data pool for genetic algorithm to solve the initially optimized problem. The papers [31-34] have discussed about application of various AI techniques in engineering problems. Paper [35-38] discuss about use of techniques such as artificial immune system, neuro-fuzzy inference technique for various engineering applications. Paper [39] discusses about dynamic study of beam type structure subjected to moving mass. Papers [40-43] discuss vibration characteristics of beam structures having faults. The papers [44-47] elaborate on Fuzzy method, Cuckoo Search method and their application in navigation and control field. Shaari et al. [48] discussed regarding crack growth in a square prismatic. Lau et al. [49] discussed regarding vibration damping behaviours of graphene reinforced nanocomposites. Er-raoudi [50] et al. used artificial neural network for fault detection of gears. Several other researchers [51-53] analyzed the mechanical properties of different forms of composite materials in relation to vibrational characterization.

Keeping in view of the limitations available in the existing literature, the current research is aimed toward development of a genetic algorithm based fault detection methodology for free-free beam.

\section{THEORETICAL ANALYSIS FOR THE DETERMINATION OF VIBRATION CHARACTERISTICS OF THE FREE-FREE BEAM IN PRESENCE OF CRACK}

An analysis of a free-free beam having a transverse crack subjected to both bending and axial load has been considered in the present study. The stiffness matrix in presence of crack is derived as the inverse of compliance matrix. The equivalent compliance matrix is derived assuming location of crack as a node element having no length and mass. Let $U_{i}=$ additional displacement due to bending load and axial load and $V_{t}=$ strain energy due to the crack.

$$
U_{i}=\frac{\partial V_{t}}{\partial P_{i}}
$$


where $V_{t}$ can be expressed as:

$$
V_{t}=\int_{0}^{a_{1}} \frac{\partial V_{t}}{\partial a} d a=\int_{0}^{a_{1}} J(a) d a
$$

where $J=\frac{\partial V_{t}}{\partial a}$ is strain energy release rate and $a_{1}$ is crack depth

By the Pari's equation, the additional displacement can be expressed as:

$$
U_{i}=\frac{\partial}{\partial P_{i}}\left[\int_{0}^{a_{1}} J(a) d a\right]
$$

The components of local flexibility matrix per unit width can be expressed as:

$$
\alpha_{i j}=\frac{\partial U_{i}}{\partial P_{j}}=\frac{\partial^{2}}{\partial P_{i} \partial P_{j}} \int_{0}^{a_{1}} J(a) d a
$$

The final resulting flexibility matrix $\left[\alpha_{i j}\right]$ over the total breadth $B$ for the beam with edge crack can be written as:

$$
\left[\alpha_{i j}\right]=\frac{\partial U_{i}}{\partial P_{j}}=\frac{\partial^{2}}{\partial P_{i} \partial P_{j}} \int_{-B / 2}^{+B / 2} \int_{0}^{a_{1}} J(a) d a d z
$$

As per Tada et al. [54]; the expression for strain energy release rate at crack location is written as:

$$
\begin{aligned}
& J=\frac{1-v_{1}^{2}}{E}\left(K_{11}+K_{12}\right)^{2} \\
& \frac{1}{E^{\prime}}=\frac{1-v_{1}^{2}}{E} \text { (plane strain) } \\
& \frac{1}{E^{\prime}}=\frac{1}{E} \text { (plane stress) }
\end{aligned}
$$

where $K_{11}$ and $K_{12}$ represent the stress intensity factors for mode I (opening of the crack) subjected under the load $P_{1}$ and $P_{2}$ defined as axial and bending load respectively. Mathematically the stress intensity factors can be written in the form as below;

$$
K_{i j}=\sigma_{i} \sqrt{\pi a}\left(F_{i}\left(\frac{a}{W}\right)\right)
$$

where $\sigma_{i}$ is stress at the crack cross section due to axial and bending load, so, 


$$
K_{11}=\frac{P_{1}}{B W} \sqrt{\pi a}\left(F_{1}\left(\frac{a}{W}\right)\right), K_{12}=\frac{6 P_{2}}{B W^{2}} \sqrt{\pi a}\left(F_{2}\left(\frac{a}{W}\right)\right)
$$

where the terms $F_{1}$ and $F_{2}$ can be expressed as:

$$
\begin{gathered}
F_{1}\left(\frac{a}{W}\right)=\left\{\frac{2 W}{\pi a} \tan \left(\frac{\pi a}{2 W}\right)\right\}^{0.5}\left\{\frac{0.752+2.02(a / W)+0.37(1-\sin (\pi a / 2 W))^{3}}{\cos (\pi a / 2 W)}\right\} \\
F_{2}\left(\frac{a}{W}\right),=\left\{\frac{2 W}{\pi a} \tan \left(\frac{\pi a}{2 W}\right)\right\}^{0.5}\left\{\frac{0.923+0.191(1-\sin (\pi a / 2 W))^{4}}{\cos (\pi a / 2 W)}\right\}
\end{gathered}
$$

Using equation (6) for strain energy release rate and putting it in equation (4), the flexibility matrix can be mathematically written as:

$$
\alpha_{i j}=\frac{B}{E^{\prime}} \frac{\partial^{2}}{\partial P_{i} \partial P_{j}} \int_{0}^{a_{1}}\left(K_{11}+K_{12}\right)^{2} d a
$$

Taking $\varphi=(a / W)$, then $d \varphi=\frac{d a}{W}$

Rearranging $d a=W d \varphi$ and when, $a=0, \varphi=0 ; a=a_{1}, \varphi=a_{1} / W=\varphi_{1}$

From the relation above, the equation (10) becomes,

$$
\alpha_{i j}=\frac{B W}{E^{\prime}} \frac{\partial^{2}}{\partial P_{i} \partial P_{j}} \int_{0}^{\varphi_{1}}\left(K_{11}+K_{12}\right)^{2} d \varphi
$$

From the equation (10), calculating $\alpha_{11}, \alpha_{12}\left(=\alpha_{21}\right)$ and $\alpha_{22}$ we get:

$$
\begin{gathered}
\alpha_{11}=\frac{B W}{E^{\prime}} \int_{0}^{\varphi_{1}} \frac{\pi a}{B^{2} W^{2}} 2\left(F_{1}\left(\varphi_{1}\right)\right)^{2} d \varphi=\frac{2 \pi}{B E^{\prime}} \int_{0}^{\varphi_{1}}\left(\varphi_{1}\right)\left(F_{1}\left(\varphi_{1}\right)\right)^{2} d\left(\varphi_{1}\right) \\
\alpha_{12}=\alpha_{21}=\frac{12 \pi}{E^{\prime} B W} \int_{0}^{\varphi_{1}}\left(\varphi_{1}\right) F_{1}\left(\varphi_{1}\right) F_{2}\left(\varphi_{1}\right) d\left(\varphi_{1}\right) \\
\alpha_{22}=\frac{72 \pi}{E^{\prime} B W^{2}} \int_{0}^{\varphi_{1}} F_{2}\left(\varphi_{1}\right) F_{2}\left(\varphi_{1}\right) d\left(\varphi_{1}\right)
\end{gathered}
$$

The inversion of compliance matrix gives rise to a local stiffness matrix i.e.

$$
K=\left[\begin{array}{ll}
K_{11} & K_{12} \\
K_{21} & K_{22}
\end{array}\right]=\left[\begin{array}{ll}
\alpha_{11} & \alpha_{12} \\
\alpha_{21} & \alpha_{22}
\end{array}\right]^{-1}
$$


Figure 1. shows a beam with width $=B$, length $=L$, depth $=W$ and depth of crack $=a_{1}$ located at distance $L_{1}$ from the left end of the beam along with the loading pattern $P_{1}$ as axial load and $P_{2}$ as bending load. Figure 2 show longitudinal and transverse amplitudes expressed as $U_{1}, U_{2}$ and $Y_{1}, Y_{2}$ respectively under transverse vibration. Influence of axial load $\left(P_{1}\right)$ and bending $\left(P_{2}\right)$, subject the beam to a coupling effect.

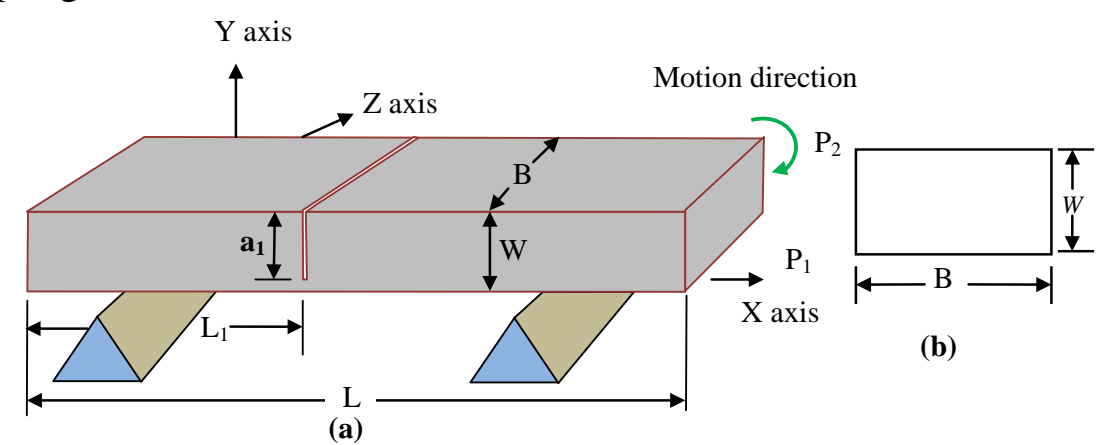

Figure 1. Beam geometry (a) free-free beam (b) Cross-sectional view of the beam.

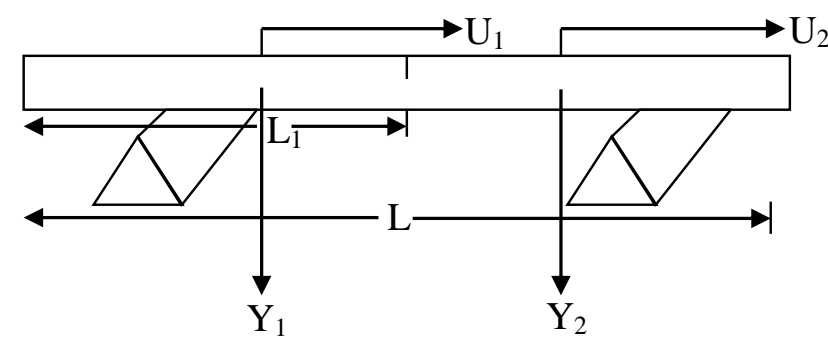

Figure 2. Free-free beam.

The normal function defined for the system can be represented as:

$$
\begin{gathered}
\bar{U}_{1}=A_{1} \cos \left(\bar{K}_{u} \bar{x}\right)+A_{2} \sin \left(\bar{K}_{u} \bar{x}\right) \\
\bar{U}_{2}=A_{3} \cos \left(\bar{K}_{u} \bar{x}\right)+A_{4} \sin \left(\bar{K}_{u} \bar{x}\right) \\
\bar{Y}_{1}(\bar{x})=A_{5} \cosh \left(\bar{K}_{y} \bar{x}\right)+A_{6} \sinh \left(\bar{K}_{y} \bar{x}\right)+A_{7} \cos \left(\bar{K}_{y} \bar{x}\right)+A_{8} \sin \left(\bar{K}_{y} \bar{x}\right) \\
\bar{Y}_{2}(\bar{x})=A_{9} \cosh \left(\bar{K}_{y} \bar{x}\right)+A_{10} \sinh \left(\bar{K}_{y} \bar{x}\right)+A_{11} \cos \left(\bar{K}_{y} \bar{x}\right)+A_{12} \sin \left(\bar{K}_{y} \bar{x}\right)
\end{gathered}
$$

where, $\bar{U}=\frac{U}{L}, \overline{\mathrm{X}}=\frac{X}{L}, \overline{\mathrm{Y}}=\frac{Y}{L}, \gamma=\frac{L_{1}}{L}, \bar{K}_{u}=\frac{\omega L}{C_{u}}, \bar{K}_{y}=\left(\frac{\omega L^{2}}{C_{y}}\right)^{1 / 2}, C_{u}=\left(\frac{E}{\rho}\right)^{1 / 2}, C_{y}=\left(\frac{E I}{\mu}\right)^{1 / 2}, \mu=A \rho$

$A_{i}(\mathrm{i}=1,12)$ are constants and their values can be calculated using boundary conditions. Following are the boundary conditions of a free-free beam under study:

$$
\left.\bar{U}_{1}^{\prime}(0)=0 ; \bar{Y}_{1}^{\prime \prime}(0)=0 ; \bar{Y}_{1}^{\prime \prime \prime} 0\right)=0 ; \bar{U}_{2}^{\prime}(1)=0 ; \bar{Y}_{2}^{\prime \prime \prime}(1)=0 ; \bar{Y}_{2}^{\prime \prime \prime}(1)=0 ;
$$

At the cracked location: 


$$
\begin{aligned}
& \bar{U}_{1}(\gamma)=\bar{U}_{2}^{\prime}(\gamma) ; \bar{Y}_{1}(\gamma)=\bar{Y}_{2}(\gamma) ; \bar{Y}_{1}^{\prime \prime}(\gamma)=\bar{Y}_{2}^{\prime \prime}(\gamma) ; \bar{Y}_{1}^{\prime \prime}(\gamma)=\bar{Y}_{2}^{\prime \prime \prime}(\gamma) \\
& \bar{U}_{2}^{\prime}(\gamma)=\bar{U}_{3}^{\prime}(\gamma) ; \bar{Y}_{2}(\gamma)=\bar{Y}_{3}(\gamma) ; \bar{Y}_{2}^{\prime \prime \prime}(\gamma)=\bar{Y}_{3}^{\prime \prime}(\gamma) ; \bar{Y}_{2}^{\prime \prime \prime}(\gamma)=\bar{Y}_{3}^{\prime \prime \prime}(\gamma)
\end{aligned}
$$

Also at the section of the crack i.e. at distance $L_{1}$, due to absence of axial displacement on both left and right side of the crack, we have:

$$
A E \frac{d U_{1}\left(L_{1}\right)}{d X}=K_{11}\left(U_{2}\left(L_{1}\right)-U_{1}\left(L_{1}\right)\right)+K_{12}\left(\frac{d Y_{2}\left(L_{1}\right)}{d X}-\frac{d Y_{1}\left(L_{1}\right)}{d X}\right)
$$

Multiplying, the term $\frac{A E}{L K_{11} K_{12}}$ on both sides of the above expression ,we get:

$$
M_{3} M_{4} \bar{y}_{1}^{\prime \prime}(\gamma)=M_{3}\left(\bar{u}_{2}(\gamma)-\bar{u}_{1}(\gamma)\right)+M_{4}\left(\bar{y}_{2}^{\prime}(\gamma)-\bar{y}_{1}^{\prime}(\gamma)\right)
$$

where,

$$
M_{1}=\frac{A E}{L K_{11}}, M_{2}=\frac{A E}{K_{12}}, M_{3}=\frac{E I}{L K_{22}}, M_{4}=\frac{E I}{L^{2} K_{21}}
$$

The boundary conditions as defined above and normal functions along with equation (15) result in the system characteristic equation as:

$$
|\psi|=0
$$

where $\psi$ is a $12 \times 12$ matrix. This characteristic equation in determinant form expressed above is a function of relative crack location $(\gamma)$, local stiffness matrix $(K)$, natural circular frequency $(\omega)$ and relative crack depth $(\varphi)$.

\section{NUMERICAL ANALYSIS TO CALCULATE RELATIVE NATURAL FREQUENCIES CONSIDERING VARIOUS CRACK DEPTHS AND CRACK LOCATIONS}

Table 1 to Table 5 present the result of numerical analysis for first three relative natural frequencies by varying relative crack depths at different relative crack locations to establish a database for validating the results with the corresponding experimental results. 
Table 1. Relative natural frequencies for a given relative crack location $=0.15$ under various relative crack depths.

\begin{tabular}{|c|c|c|c|}
\hline \multirow[b]{2}{*}{$\begin{array}{c}\text { Relative crack } \\
\text { depth }\end{array}$} & \multicolumn{3}{|c|}{ Crack location $($ relative $)=0.15$} \\
\hline & $\begin{array}{c}\text { Relative natural } \\
\text { frequency } \\
\text { (first) }\end{array}$ & $\begin{array}{c}\text { Relative natural } \\
\text { frequency } \\
\text { (second) }\end{array}$ & $\begin{array}{c}\text { Relative natural } \\
\text { frequency } \\
\text { (third) }\end{array}$ \\
\hline 0.05 & 0.96427 & 0.97409 & 0.95994 \\
\hline 0.15 & 0.96204 & 0.97248 & 0.95744 \\
\hline 0.25 & 0.95982 & 0.970873 & 0.95495 \\
\hline 0.35 & 0.95759 & 0.96925 & 0.95245 \\
\hline 0.45 & 0.95537 & 0.96764 & 0.94996 \\
\hline 0.55 & 0.95314 & 0.96603 & 0.94746 \\
\hline
\end{tabular}

Table 2. Relative natural frequencies for a given relative crack location $=0.25$ under various relative crack depths.

\begin{tabular}{cccc}
\hline \multirow{2}{*}{$\begin{array}{c}\text { Relative crack } \\
\text { depth }\end{array}$} & \begin{tabular}{c} 
Crack location(relative)= 0.25 \\
\cline { 2 - 4 } Relative natural \\
frequency(first)
\end{tabular} & $\begin{array}{c}\text { Relative natural } \\
\text { frequency } \\
\text { (second) }\end{array}$ & $\begin{array}{c}\text { Relative natural } \\
\text { frequency } \\
\text { (third) }\end{array}$ \\
\hline 0.05 & 0.98238 & 0.93647 & 0.93146 \\
0.15 & 0.98128 & 0.93251 & 0.92720 \\
0.25 & 0.98018 & 0.92856 & 0.92293 \\
0.35 & 0.97909 & 0.92460 & 0.91866 \\
0.45 & 0.97799 & 0.92065 & 0.91439 \\
0.55 & 0.97689 & 0.91669 & 0.91012 \\
\hline
\end{tabular}

Table 3. Relative natural frequencies for a given relative crack location $=0.35$ under various relative crack depths.

\begin{tabular}{cccc}
\hline \multirow{2}{*}{$\begin{array}{c}\text { Relative crack } \\
\text { depth }\end{array}$} & \multicolumn{3}{c}{ Crack location(relative)= 0.35 } \\
\cline { 2 - 4 } & $\begin{array}{c}\text { Relative natural } \\
\text { frequency } \\
\text { (first) }\end{array}$ & $\begin{array}{c}\text { Relative natural } \\
\text { frequency } \\
\text { (second) }\end{array}$ & $\begin{array}{c}\text { Relative natural } \\
\text { frequency } \\
\text { (third) }\end{array}$ \\
\hline 0.05 & 0.96076 & 0.93628 & 0.97909 \\
0.15 & 0.95795 & 0.93232 & 0.97779 \\
0.25 & 0.95549 & 0.92835 & 0.97649 \\
0.35 & 0.95330 & 0.92438 & 0.97518 \\
0.45 & 0.95056 & 0.92041 & 0.97388 \\
0.55 & 0.94809 & 0.91644 & 0.97258 \\
\hline
\end{tabular}


Table 4. Relative natural frequencies for a given relative crack location $=0.45$ under various relative crack depths.

\begin{tabular}{cccc}
\hline \multirow{2}{*}{$\begin{array}{c}\text { Relative crack } \\
\text { depth }\end{array}$} & $\begin{array}{c}\text { Relative natural } \\
\text { frequency } \\
\text { (first) }\end{array}$ & $\begin{array}{c}\text { Relative natural } \\
\text { frequency } \\
\text { (second) }\end{array}$ & $\begin{array}{c}\text { Relative natural } \\
\text { frequency } \\
\text { (third) }\end{array}$ \\
\hline 0.05 & 0.93660 & 0.95338 & 0.93502 \\
0.15 & 0.93265 & 0.95048 & 0.93097 \\
0.25 & 0.92869 & 0.94758 & 0.92692 \\
0.35 & 0.924750 & 0.94468 & 0.92287 \\
0.45 & 0.92080 & 0.94177 & 0.91883 \\
0.55 & 0.916856 & 0.93887 & 0.91478 \\
\hline
\end{tabular}

Table 5: Relative natural frequencies for a given relative crack location $=0.55$ under various relative crack depths.

\begin{tabular}{cccc}
\hline \multirow{2}{*}{$\begin{array}{c}\text { Relative crack } \\
\text { depth }\end{array}$} & $\begin{array}{c}\text { Relative natural } \\
\text { frequency } \\
\text { (first) }\end{array}$ & $\begin{array}{c}\text { Relative natural } \\
\text { frequency } \\
\text { (second) }\end{array}$ & $\begin{array}{c}\text { Relative natural } \\
\text { frequency } \\
\text { (third) }\end{array}$ \\
\hline 0.05 & 0.93642 & 0.95151 & 0.93596 \\
0.15 & 0.92959 & 0.94849 & 0.93197 \\
0.25 & 0.92546 & 0.94547 & 0.92798 \\
0.35 & 0.92133 & 0.94245 & 0.92399 \\
0.45 & 0.91720 & 0.93943 & 0.92000 \\
0.55 & 0.91308 & 0.93641 & 0.91601 \\
\hline
\end{tabular}

\section{EXPERIMENTAL SETUP}

Initially, an aluminum beam specimen of length $100 \mathrm{~cm}$, width $50 \mathrm{~mm}$ and thickness $8 \mathrm{~mm}$ is made for carrying out experiment. Before the experiment is carried out, a transverse crack is created using a wire cut electrode discharge machine. Following the same procedure, no of specimens are made with cracks at different relative crack locations from one end $(0.15,0.25$, $0.35,0.45$, and 0.55$)$ with different relative crack depths $(0.15,0.25,0.35,0.45$, and 0.55$)$ in each specimen. A vibration testing machine (pulse lite 3560-L machine) was used to study the mode shapes and record natural frequency change of the test beam subjected to free vibration with and without a crack. Specific experiments were conducted step by step with varying locations and crack depths in a systematic manner. As a part of experimental procedure, the specimens were placed in a test rig (Figure 3) with a free-free end conditions and tests were conducted systematically considering different parameters like crack locations, and crack depths. The initial excitation was given on the mid span of the beam using a specialized hammer. To register the 1st, 2nd and 3rd modes of vibration, a piezoelectric accelerometer was placed along the length of beam. The signals representing natural frequency and mode shapes were captured in a vibration analyzer consisting of frequency response spectrum, printer and a desktop computer with dual channel analyzer. The experimental result of corresponding amplitudes is recorded in a digital storage oscilloscope at various crack location along the beam length. 


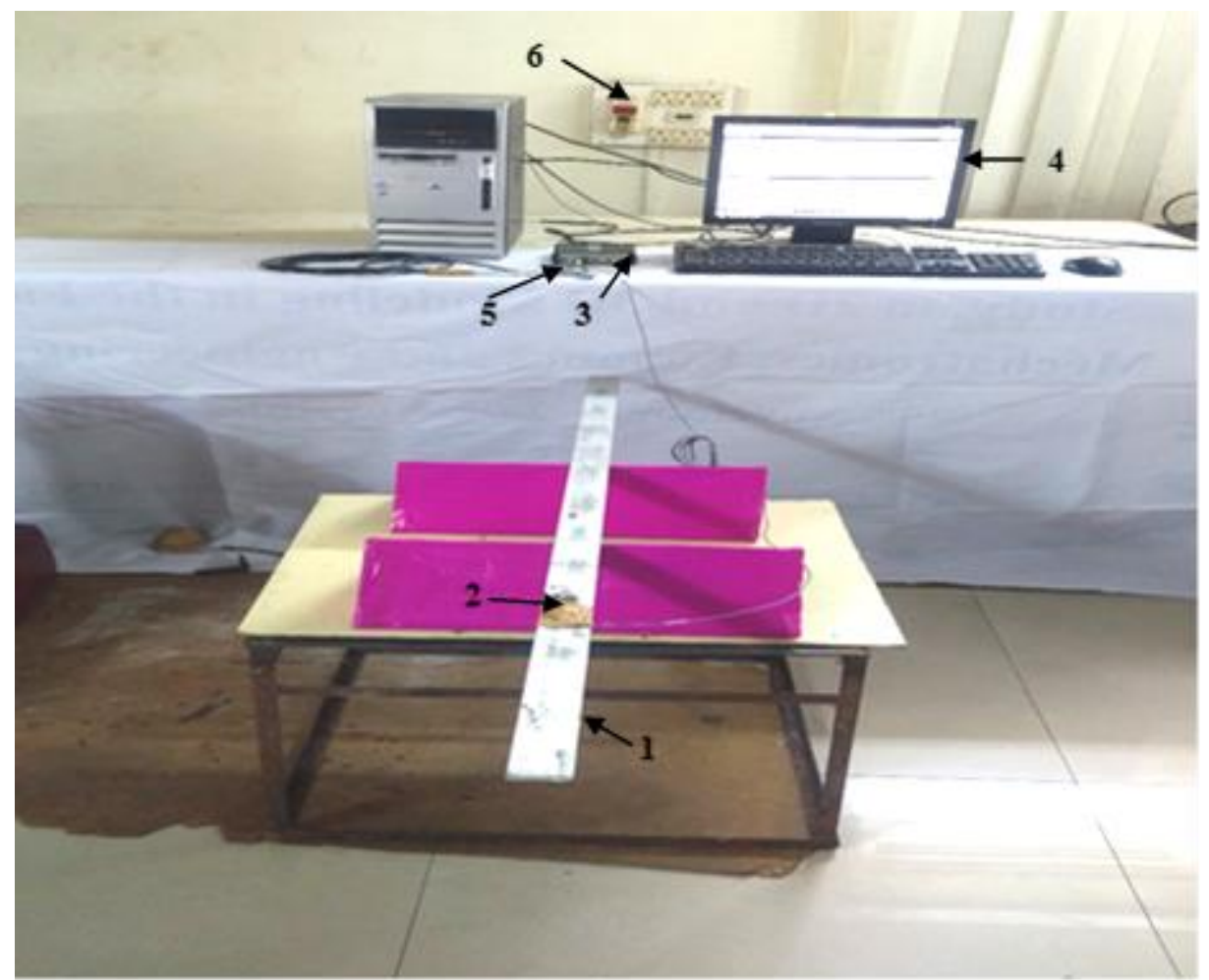

Figure 3. Experimental set up. (1-Cracked beam, 2-Vibration pick-up, 3-Vibration analyzer, 4-Vibration indicator, 5-Impact Hammer, 6-Power source)

\section{GRAPHICAL PRESENTATION OF MODE SHAPES OF NUMERICAL AND EXPERIMENTAL ANALYSIS}

The following figures represent a comparative study of numerical and experimental analysis at different crack depth and crack locations for different mode shapes of a cracked free-free beam.

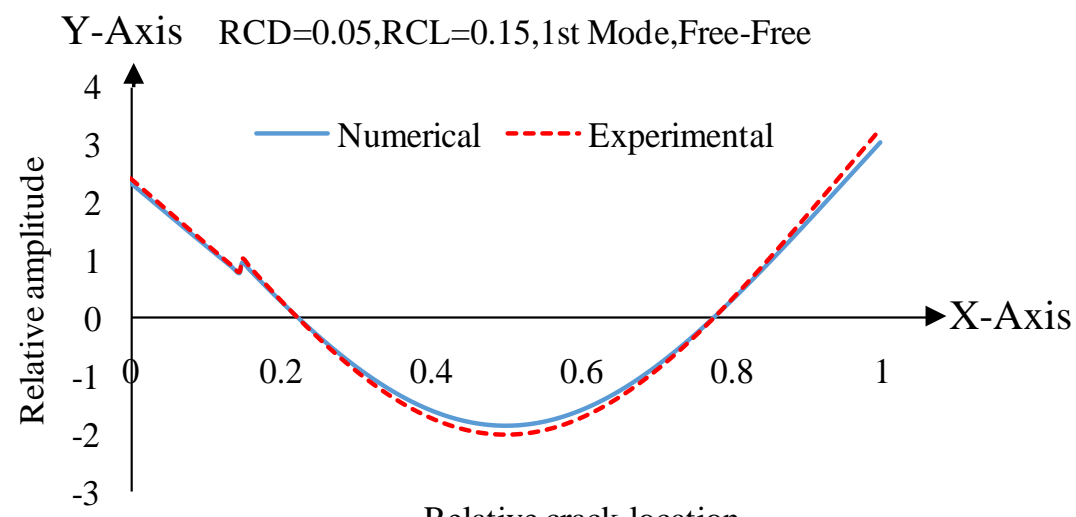

Relative crack location

Figure $4.1^{\text {st }}$ mode of vibration for free- free beam with $\mathrm{RCD}=0.05, \mathrm{RCL}=0.15$. 


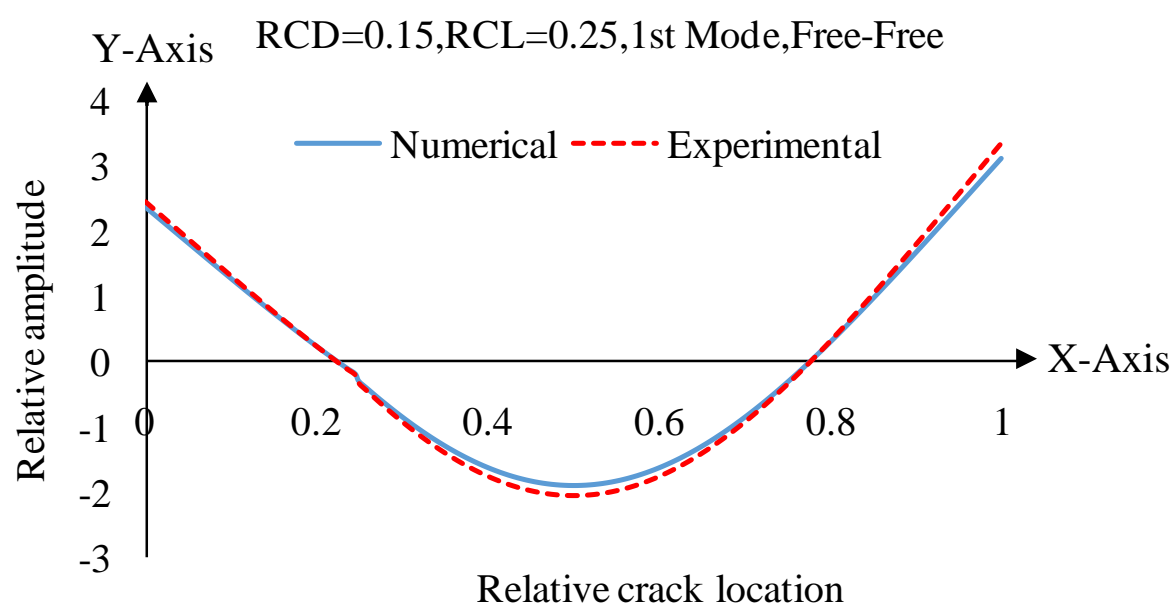

Figure $5.1^{\text {st }}$ mode of vibration for free- free beam with $\mathrm{RCD}=0.15, \mathrm{RCL}=0.25$.

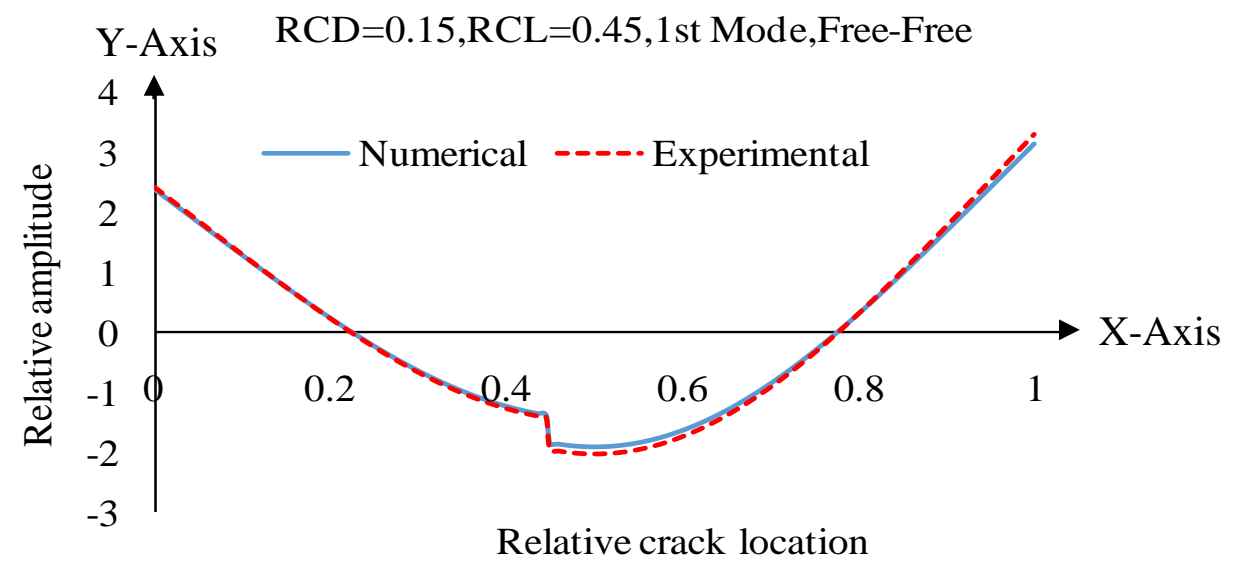

Figure 6. $1^{\text {st }}$ mode of vibration for free- free beam with $\mathrm{RCD}=0.15, \mathrm{RCL}=0.45$.

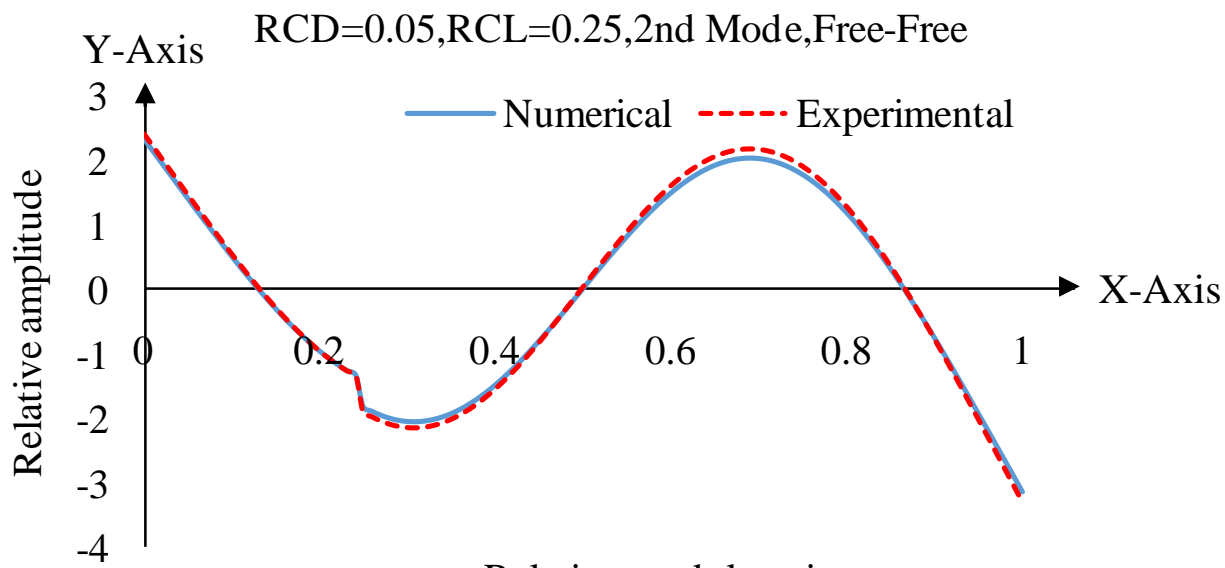

Relative crack location

Figure 7. $2^{\text {nd }}$ mode of vibration for free- free beam with $\mathrm{RCD}=0.05, \mathrm{RCL}=0.25$. 


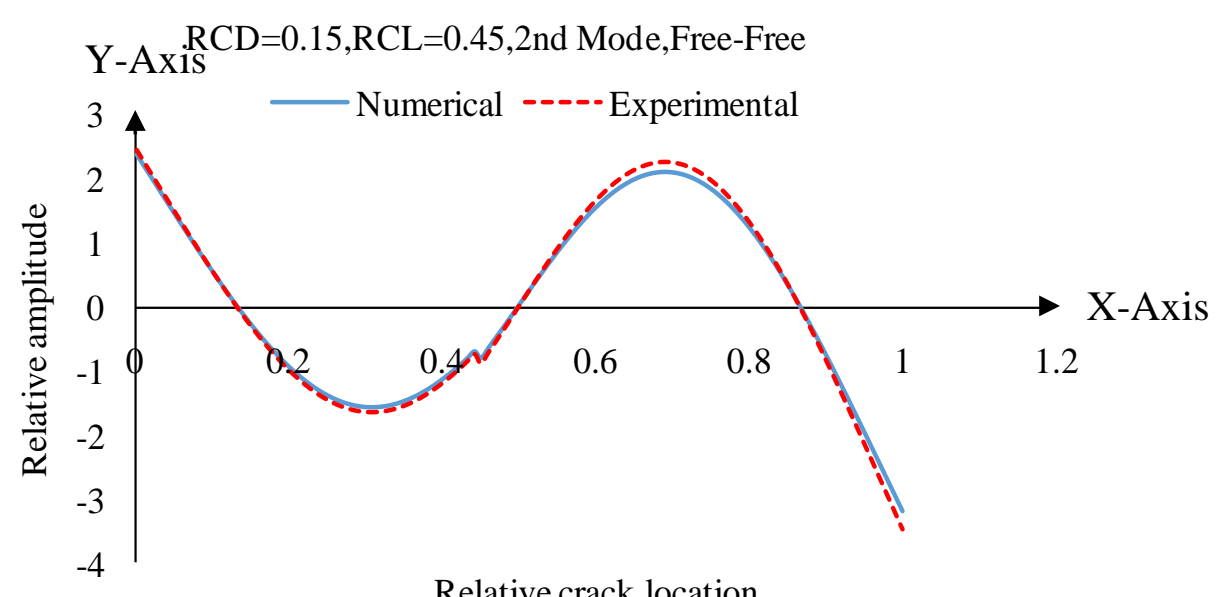

Figure 8. $2^{\text {nd }}$ mode of vibration for free- free beam with $\mathrm{RCD}=0.15, \mathrm{RCL}=0.45$.

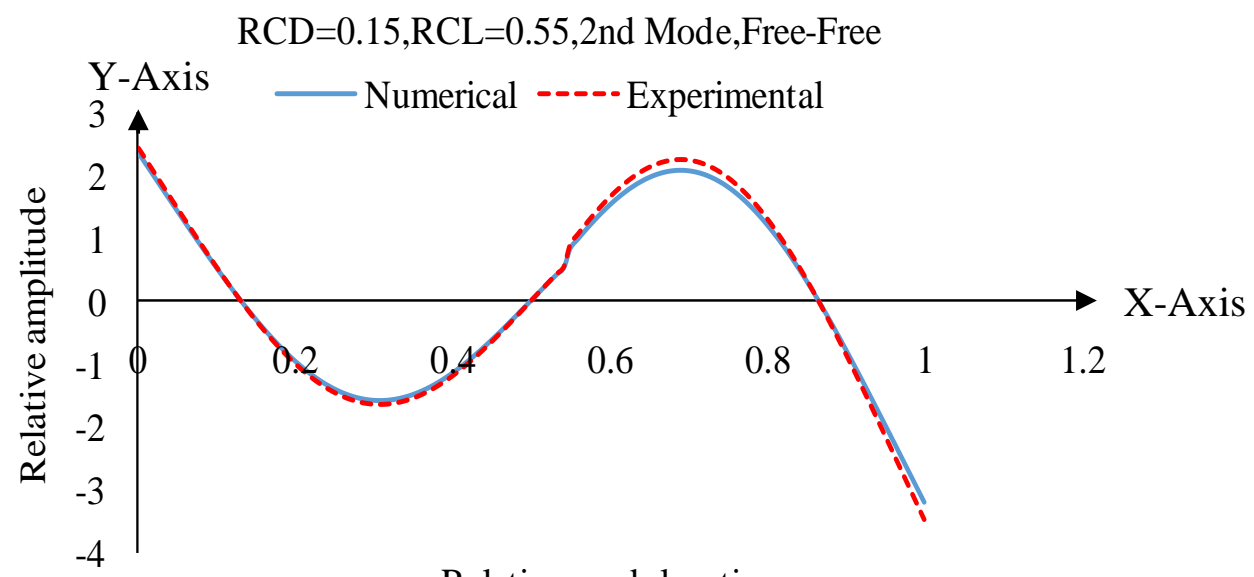

Relative crack location

Figure $9.2^{\text {nd }}$ mode of vibration for free- free beam with $\mathrm{RCD}=0.15, \mathrm{RCL}=0.55$.

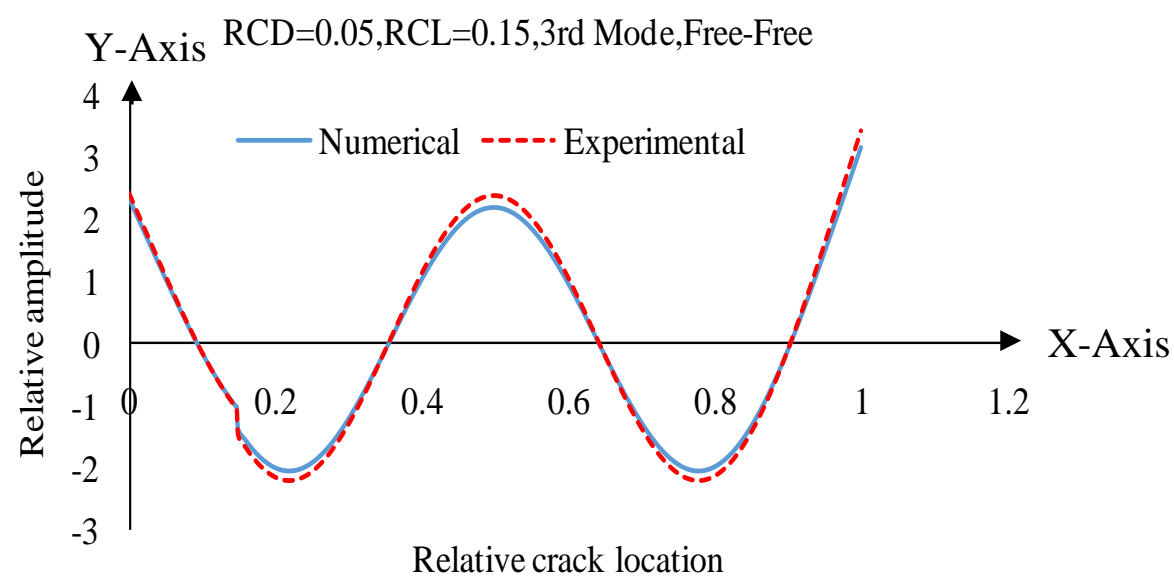

Figure 10. $3^{\text {rd }}$ mode of vibration for free- free beam with $\mathrm{RCD}=0.05, \mathrm{RCL}=0.15$. 


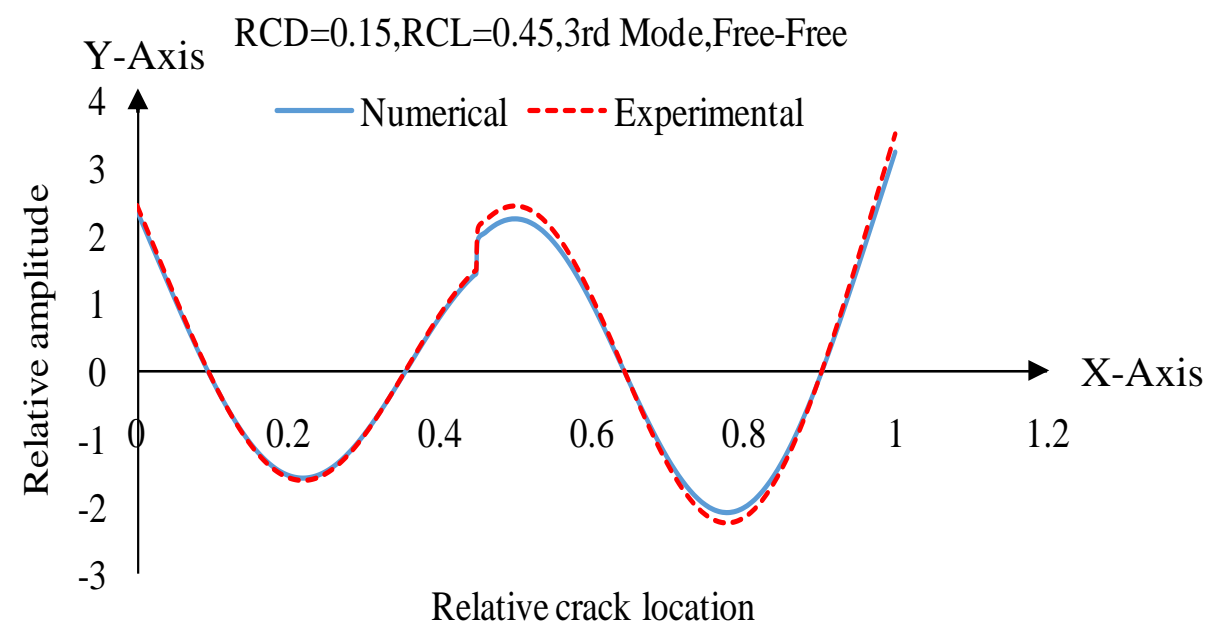

Figure 11. $3^{\text {rd }}$ mode of vibration for free- free beam with $\mathrm{RCD}=0.15, \mathrm{RCL}=0.45$.

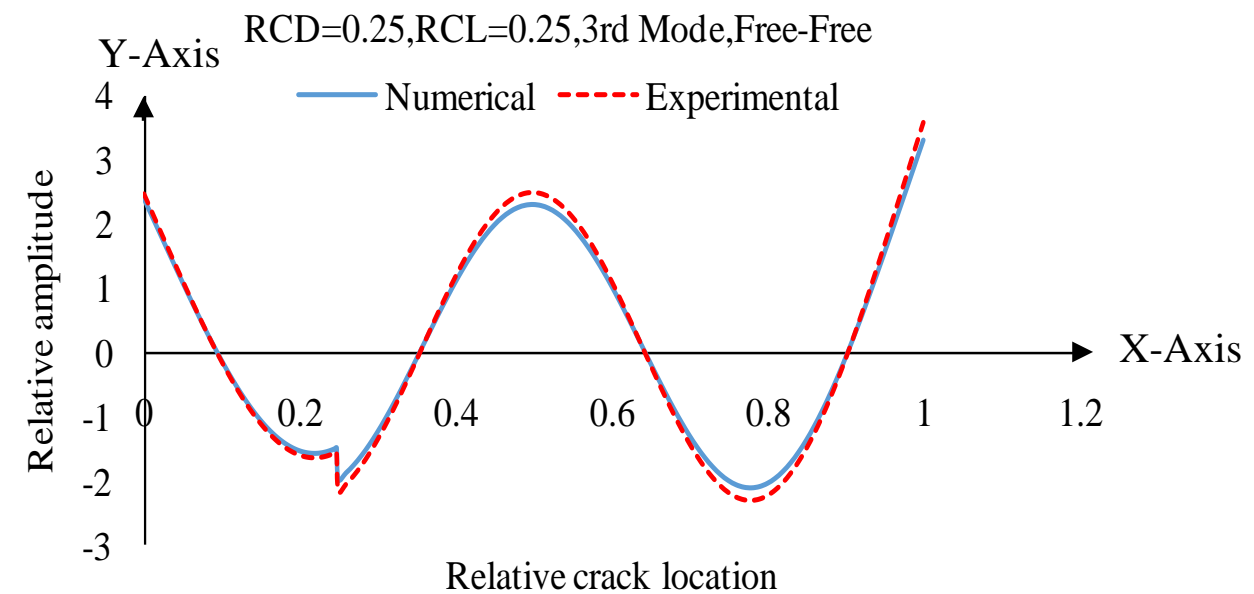

Figure 12. $3^{\text {rd }}$ mode of vibration for free- free beam with $\mathrm{RCD}=0.25, \mathrm{RCL}=0.25$.

\section{THE PRINCIPLE OF WORKING OF GENETIC ALGORITHM}

The principle of working of the technique is a Darwin's theory based population survey that encompasses a procedure for selection of a set of chromosomes, a set of gene with a set of population capable of mutation and breeding. The procedure initiates with a solution set representing chromosomes as population. The new population is generated from a set of old population on the criteria of fitness. The Evaluation procedure is continued under the motivation that the new population is better in fitness than the previous one. On the basis of fitness criteria, new offspring are generated as a part of new solutions. The above process is repeated until some conditions are attained. 


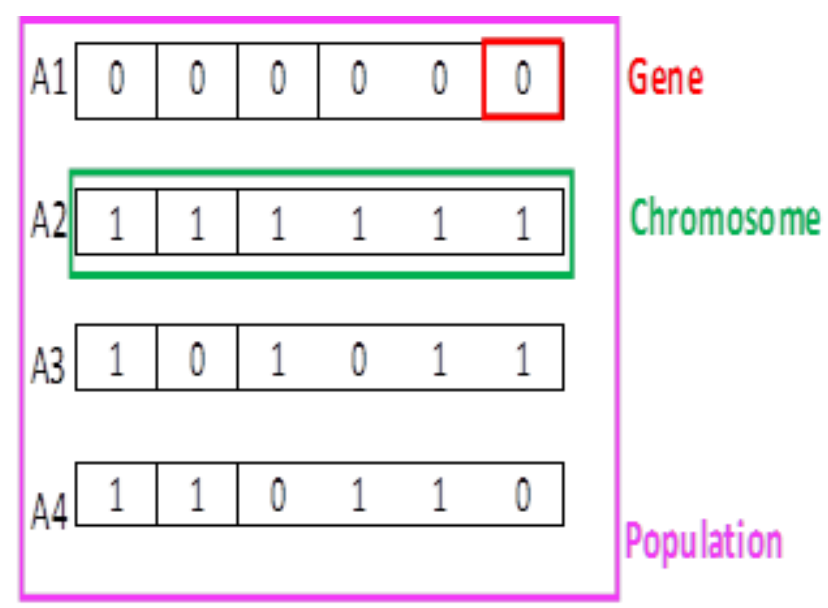

Figure 13. Population, chromosome and gene.

\section{Initial Population}

A database of initial population is created using a set of individuals called chromosomes. Each individual chromosome is characterized by a set of variables known as genes associated with binary values 1 or 0 . Genes are joined as string to form a Chromosome (solution). Parent chromosomes were chosen from a population set based on fitness. Chromosomes with better fitness are more likely to be considered as parent chromosomes.

\section{Selection}

Parent chromosomes were chosen from a population set based on fitness. Chromosomes with better fitness are more likely to be considered as parent chromosomes. Two pairs of individuals as chromosomes (parents) are selected purely on their fitness scores that approach to the field variables. Individuals with better fitness values are more likely to be selected for reproduction.

\section{Crossover}

Crossover is the most significant step in the genetic algorithm process. The crossover process of parent chromosomes create offspring called as children. In absence of any crossover, offspring are considered as the exact copy of the parent chromosomes. For each pair of parents, a single crossover point is randomly chosen within the genes of the chromosomes and then exchanged themselves as shown below to create new offspring. Two-parent crossover gives rise to two new offspring. Cross over is controlled by cross over rate. 

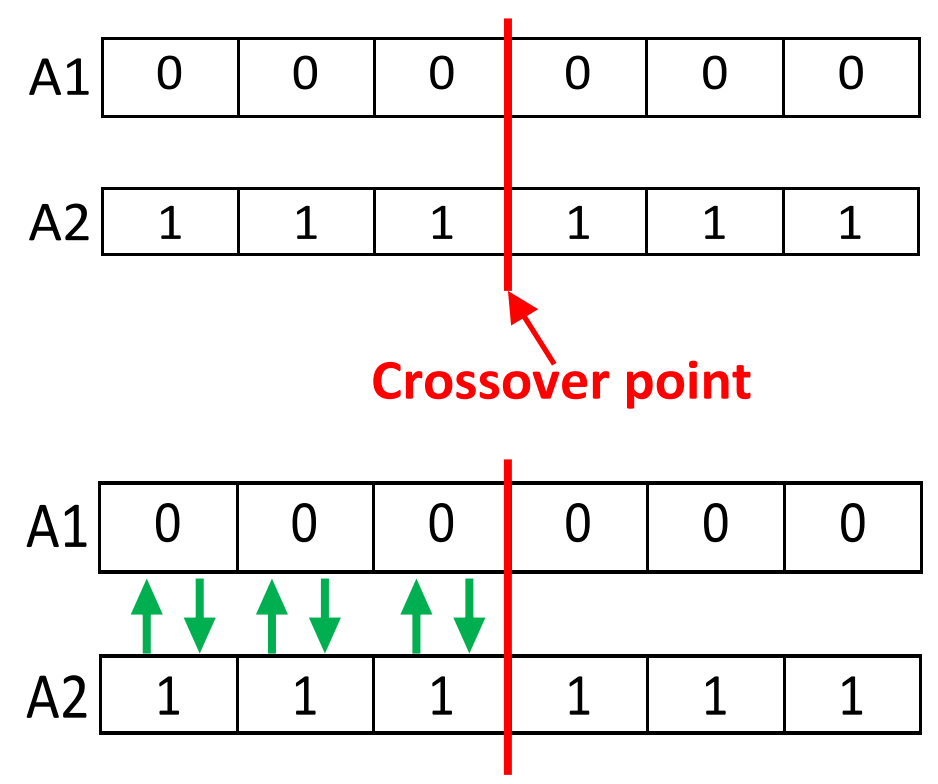

Single point crossover of parents A1 and A2

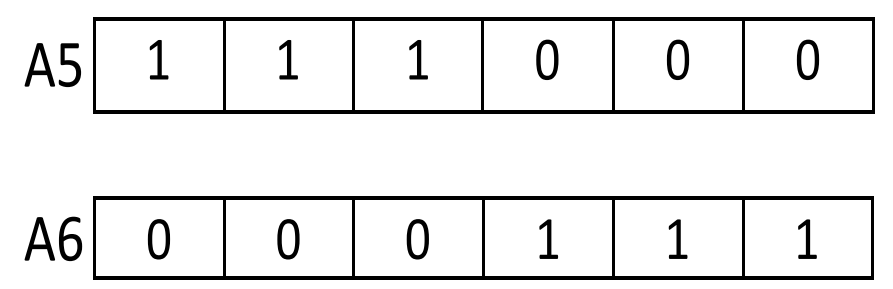

New offspring A5 and A6 after single point crossover

Figure 14. Single point crossover to generate new offspring.

\section{Mutation}

In simple term, from the new offspring's formed by crossover, it is possible to change the fitness of the new individual by a small random tweak in their genes through a process called mutation. This genetic process is desirable to introduce diversity in the population search and to stop any premature convergence. When the algorithm process terminates and does not produce any further offspring that is different from the previous one it is said to have provided a solution to the problem. Mutation is a significant genetic operator. It is intended to oppose the decreasing rate of solution. It has been observed that mutation is essential to the convergence of the genetic algorithm solution, while cross over is not. Mutation is generally applied only when it is beneficial. Various types of mutation operators used are: 


Before Mutation
\begin{tabular}{|c|c|c|c|c|c|}
\hline 1 & 1 & 1 & 0 & 0 & 0 \\
\hline
\end{tabular}

\section{After Mutation}

A5 \begin{tabular}{|l|l|l|l|l|l|}
\hline 1 & 1 & 0 & 1 & 1 & 0 \\
\hline
\end{tabular}

Figure 15. Mutation: Before and After.

\section{Bit flip mutation}

In a bit flip mutation technique, one or more random bits from a binary string are selected and flipped either from 0 to 1 or from 1 to 0 . This is used for binary encoded genetic algorithm.

\begin{tabular}{|l|l|l|l|l|l|l|l|l|l|}
\hline 0 & 0 & 1 & 1 & 0 & 1 & 0 & 0 & 1 & 0 \\
\hline
\end{tabular}

Individual chromosome before mutation

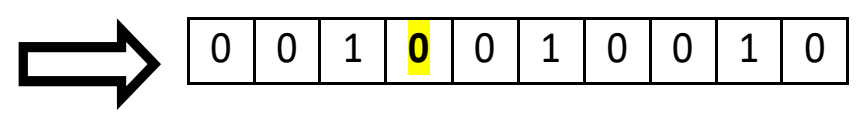

Individual chromosome after mutation

Figure 16. Bit flip mutation process.

\section{Swap Mutation}

In this swap mutation, two positions in the chromosome are interchange with their associated value. This is common in permutation based encoding.

\begin{tabular}{|ll|l|l|l|ll|l|l|l|l|}
\hline 1 & 2 & 3 & 4 & 5 & $\mathbf{6}$ & 7 & 8 & 9 & 0 \\
$\longrightarrow$
\end{tabular} \begin{tabular}{|l|l|l|l|l|l|l|l|l|l|}
\hline & $\mathbf{6}$ & 3 & $\mathbf{4}$ & $\mathbf{5}$ & $\mathbf{2}$ & $\mathbf{7}$ & 8 & 9 & 0 \\
\hline
\end{tabular}

Individual chromosome before mutation Individual chromosome after mutation Figure 17. Swap mutation process.

\section{Scramble mutation}

Scramble mutation is a popular mutation technique with permutation representation. In this, a sub set of genes is chosen from the entire string, and their values are shuffled or scrambled randomly.

\section{\begin{tabular}{|ll|l|ll|l|l|ll|l|}
\hline 0 & 1 & $\mathbf{2}$ & $\mathbf{3}$ & $\mathbf{4}$ & $\mathbf{5}$ & $\mathbf{6}$ & $\mathbf{7}$ & 8 & 9 \\
\hline
\end{tabular}}

Individual chromosome before mutation

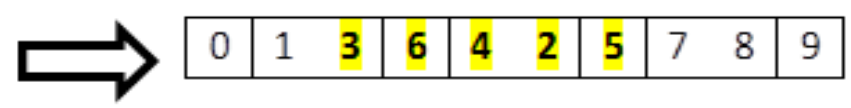

Individual chromosome after mutation Figure 18. Scramble mutation process.

\section{Inversion mutation}

In such mutation technique, a subset of genes is chosen from the entire string and their positions are entirely inversed.

\begin{tabular}{|l|l|l|l|l|l|l|l|l|l|}
\hline 0 & 1 & 2 & 3 & $\mathbf{4}$ & $\mathbf{5}$ & $\mathbf{6}$ & $\mathbf{7}$ & 8 & 9 \\
\hline
\end{tabular}

Individual chromosome before mutation

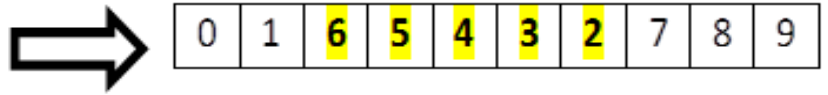

Individual chromosome after mutation

Figure 19. Inversion mutation process. 
In the present study, binary encoding mutation technique has been adopted. In such encoding system the bits selected for generating new offspring are inserted as illustrated. In binary encoding mutation, the bit 1 is turned to bit 0 , it reduces the numerical values associated with the chromosomes and is referred as up mutation.

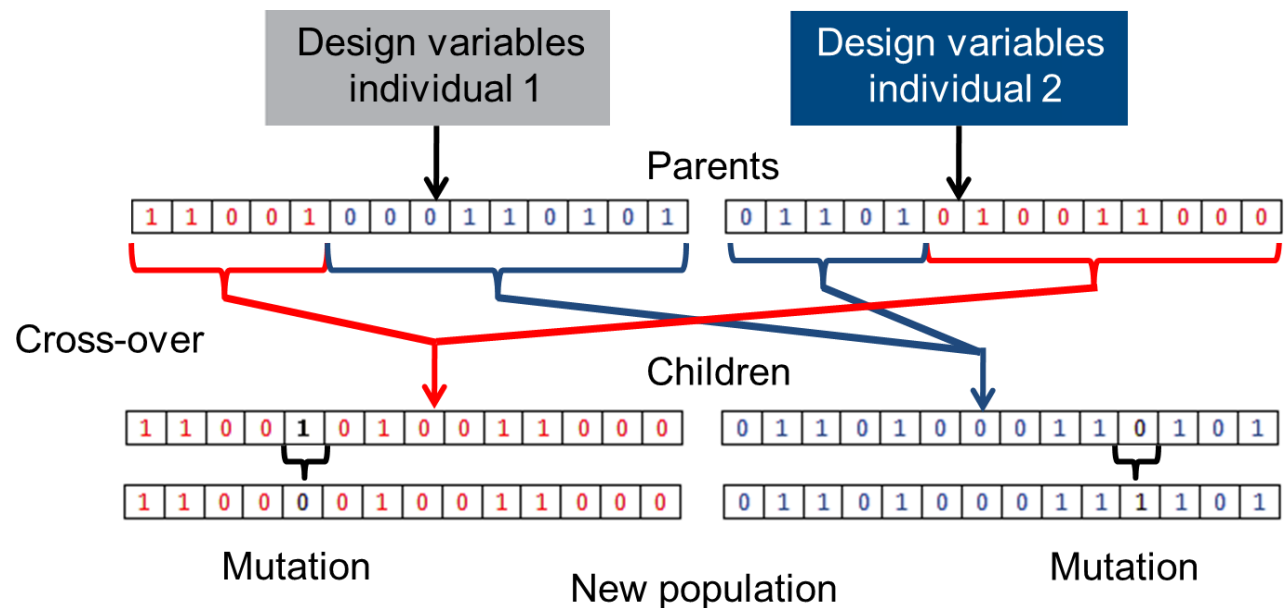

Figure 20. Genetic algorithm operators.

The outline of the genetic algorithm procedure is presented as follows.

Step-1: Under population survey, chromosomes as parent population are selected from a data pool of random population as input parameters to the model.

Step-2: Fitness of each chromosome as parent population are evaluated from the selected population

Step-3: Crossover/mutation of parents to create offspring

Step-4: Evaluation of fitness of offspring using objective function

Step-5: Output evaluation from the offspring and parents.

Following steps are performed to create new population

5(a) (selection) Parent chromosomes were chosen from a population set based on fitness. Chromosomes with better fitness are more likely to be considered as parent chromosomes.

5(b) (crossover) the process of crossover of parent chromosomes create offspring called as children. In absence of any crossover, offspring are considered as the exact copy of the parent chromosomes.

5(c) (mutation) the mutation of offspring creates new offspring. New offspring created are then placed in new population.

Step-6: (output) the new population generated are then run for the algorithm for evaluation of output

Step-7: (test) The program are then continued to run till the end conditions are achieved, then stop and then return to the best solution in the current existing population.

Step-8: (loop) step (5-b) were repeated.

The crossover and mutation process largely influence the GA's performance. 


\section{ANALYSIS OF CRACK DIAGNOSTIC TOOL USING GENETIC ALGORITHM}

Genetic algorithm is a natural selection and genetic based optimisation methodology that is mainly designed to asses effectively for nonlinear applications in a better way in comparison to traditional optimization technique. Further this online assessment is helpful where availability of experience or specialized expert information is scarce or there is difficulty in modeling the problem. The Genetic algorithm comprises of an array of genes and its chromosomes. Each chromosome is treated as an individual in resemblance to the nature. Each chromosome is optimized for its environment and is developed through successive modifications from a no. of generations. The technique is largely accepted as an optimized tool for wide variety of applications in various fields. So for its versatile applicability, Genetic algorithm has been used as a methodology for crack identification in a beam structure. The Genetic algorithm technique adopts the chromosomes which are composed of vibrational parameters like relative natural frequencies, relative mode shapes, relative crack location and relative crack depth. The modal vibration parameters obtained from analytical and numerical investigations are used to create the database for the proposed technique. The proposed model uses large no of chromosomes from the database that act as parent chromosomes. In the present work, every parent chromosome will be attached with relative first three natural frequencies as input data with relative crack location and depth as output data.

An initial data pool of different vibration parameters such as first, second and third relative natural frequencies, relative crack location and relative crack depth is created using the results of numerical and theoretical analysis of the beam under test. The vibration parameters which are considered as a set of variables treated as genes of individual chromosomes associated with binary values 1 or 0 . These genes are connected in the form of a string called chromosome. A set of chromosomes form a population set. Parent chromosomes were chosen from the population set based on fitness. Chromosomes with better fitness are more likely to be considered as parent chromosome.

Stage-1: Prediction using data pool set

The initial data pool is obtained from the calculated values of vibration parameters of analytical and numerical results for a free-free beam of specific dimension. All individual data set is represented as chromosome, derived from the developed data pool for the model. In this study, data set has been used from the field to obtain the optimized solution. Thus a search space of different modal parameters is created for the proposed investigations. The relative crack location and crack depth are the output data of the proposed methodology.

The initial population with size $n$ is expressed as

Initial population $P=\left\langle L_{1}, L_{2}, L_{3} \ldots \ldots L_{n}\right\rangle$ where $L_{1}, L_{2}, L_{3}$ are population member of initial population $P$

If $L_{i, j}=$ no of elements called genes of each population member $\mathrm{Li}$

Let every population member consists of five no of genes i.e. $L_{1}=\left\{L_{1,1}, L_{1,2}, L_{1,3}, L_{1,4}, L_{1,5}\right\}$, $L_{2}=\left\{L_{2,1}, L_{2,2}, L_{2,3}, L_{2,4}, L_{2,5}\right\}, L_{3}=\left\{L_{3,1}, L_{3,2}, L_{3,3}, L_{3,4}, L_{3,5}\right\}, L_{n}=\left\{L_{n, 1}, L_{n, 2}, L_{n, 3}, L_{n, 4}, L_{n, 5}\right\}$

where, Element no -a $\left(L_{1,1}\right.$ to $\left.L_{n, 1}\right)$ represented as the first relative natural frequency (frnf), Element no -b $\left(L_{1,2}\right.$ to $\left.L_{n, 2}\right)$ represented as the second relative natural frequency (srnf), Element no -c ( $L_{1,3}$ to $\left.L_{n, 3}\right)$ represented as the third relative natural frequency (trnf), Element no -d $\left(L_{1,4}\right.$ to $\left.L_{n, 4}\right)$ represented as $\left(r c l_{1}\right)$ and is defined as the relative first crack location, Element no -e $\left(L_{1,5}\right.$ to $\left.L_{n, 5}\right)$ represented as $\left(r c d_{1}\right)$ and is defined as the relative first crack depth 
Genetic algorithm uses the relative natural frequency as input data with crack location and crack depth as output data for identifying crack position and depth of crack.

Stage-2: Objective function and Fitness function

To improve the process of damage detection and to minimize computational time it is necessary to consider an objective function appropriate to the problem. If more genes in selected chromosomes come up with binary values 1's then it is considered to be of maximum fitness. An optimal solution is only possible if the objective function is quantified and minimized so that it gives the best outcome from a given population. In the present, work the objective function $(J)$ in terms of frequency difference is given as:

$$
J=\left\{\left(f r n f_{f g}-f r n f_{x g}\right)^{2}+\left(s r n f_{f g}-s r n f_{x g}\right)^{2}+\left(\operatorname{trnf} f_{f g}-\operatorname{trnf} f_{x g}\right)^{2}\right\}^{0.5}
$$

where, $g$ represents the no of generation, subscript $f$ and $x$ represent field and experimental counterpart respectively and $f r n f, \operatorname{srnf}$, trnf are first, second and third relative natural frequency.

A fitness function determines the closeness of the solution to the optimum solution of the desired problem. A fitness value is allocated to each string to indicate the closeness to the overall specification of the desired problem. The fitness value will assume the feature of the solution. Normally the fitness function is derived from the objective function. For the minimization problem the fitness function may be considered to be the same as the objective function, while a maximize problem can be converted into a minimization problem defining the fitness function The fitness value can be changed from time to time to generate new strings which is assumed to execute with better performance than the former generation. The fitness function defined in terms of objective function is considered as below

$$
\mu=\frac{1}{1+J}
$$

where $\mu$ is the fitness function.

Stage-3 Cross over for offspring

This stage deals with the offspring reproduction by cross over operation by selecting the suitable parent chromosomes from the search space. Two no of offspring chromosomes are produced from the combination of selected parent chromosomes by a single point cross over technique using the encoded data of gene information. Then the optimal solution is obtained by analyzing offspring chromosomes. 
Cross over for fnf

\begin{tabular}{|c|c|c|c|c|c|c|c|c|c|c|c|c|c|c|c|c|c|c|c|}
\hline \multicolumn{10}{|c|}{ Parent 1} & \multicolumn{10}{|c|}{ Offspring 1} \\
\hline 1 & 1 & 0 & 1 & 0 & 1 & 0 & 1 & 0 & 1 & 1 & 1 & 0 & 1 & 0 & 1 & 0 & 1 & 1 & 0 \\
\hline \multicolumn{10}{|c|}{$\begin{array}{l}\text { Crossover point } \\
\text { Parent } 2\end{array}$} & \multicolumn{5}{|c|}{ Offspring 2} & & & & & \\
\hline 1 & 1 & 1 & 0 & 1 & 1 & 0 & 1 & 1 & 0 & 1 & 1 & 1 & 0 & 1 & 1 & 0 & 1 & 0 & 1 \\
\hline
\end{tabular}

Cross over for snf

\begin{tabular}{|c|c|c|c|c|c|c|c|c|c|c|c|c|c|c|c|c|c|c|c|}
\hline \multicolumn{10}{|c|}{ Parent 1} & \multicolumn{10}{|c|}{ Offspring 1} \\
\hline 1 & 0 & 1 & 1 & 0 & 1 & O & 1 & O & 1 & 1 & 0 & 1 & 1 & 0 & 0 & 1 & 1 & 1 & 0 \\
\hline \multicolumn{20}{|c|}{$\begin{array}{l}\text { Crossover point } \\
\text { Parent } 2\end{array}$} \\
\hline 0 & 1 & 1 & 0 & 1 & 0 & 1 & 1 & 1 & 0 & 0 & 1 & 1 & 0 & 1 & 1 & 0 & 1 & 0 & 1 \\
\hline
\end{tabular}

Cross over for tnf

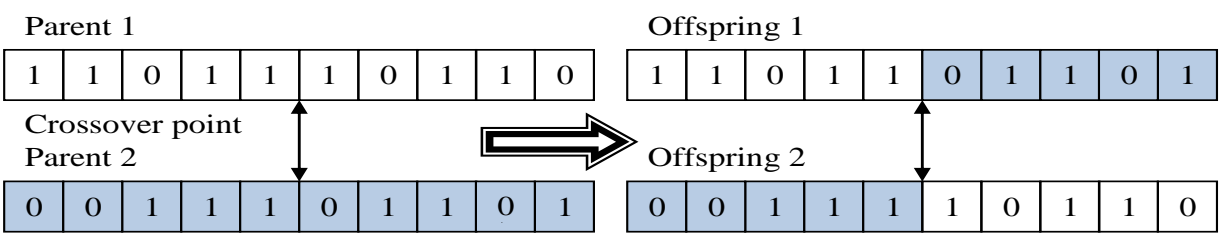

Cross over for rel

\begin{tabular}{|c|c|c|c|c|c|c|c|c|c|c|c|c|c|c|c|c|c|c|c|}
\hline \multicolumn{10}{|c|}{ Parent 1} & \multicolumn{10}{|c|}{ Offspring 1} \\
\hline 0 & 1 & 1 & 0 & 0 & 1 & 1 & 0 & 1 & 0 & 0 & 1 & 1 & 0 & 0 & 0 & 1 & 1 & 0 & 1 \\
\hline \multicolumn{10}{|c|}{$\begin{array}{l}\text { Crossover point } \\
\text { Parent } 2\end{array}$} & \multicolumn{5}{|c|}{ Offspring 2} & & & & & \\
\hline 1 & 1 & 1 & 0 & 1 & 0 & 1 & 1 & 0 & 1 & 1 & 1 & 1 & 0 & 1 & 1 & 1 & 0 & 1 & 0 \\
\hline
\end{tabular}

Cross over for red

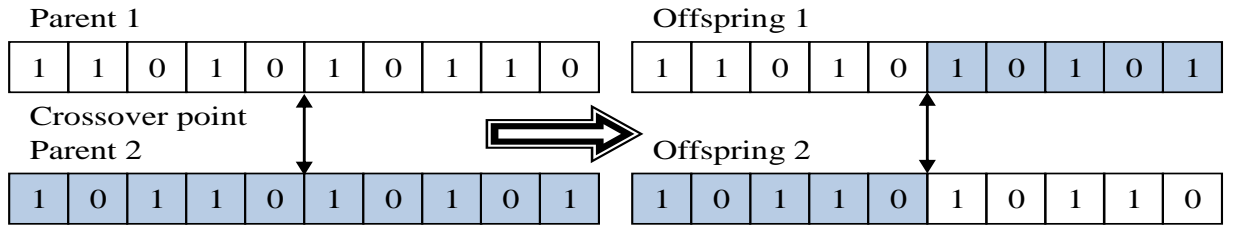

Figure 21. Single point cross over technique for creating new offspring.

Stage 4: Mutation of the genes

The altering of binary code of the existing genes, the mutation process give rise to a new set of genes leading to a new set of genetic pattern in the search space and an optimal solution is possible by evaluating the fitness of the chromosomes with the mutated genes. The adopted natural selection process plays a vital role in deciding the fate of mutated chromosomes.

The best-fitted chromosomes among the general population are the deciding factor to be allowed for mating with other fitted chromosomes. If the mutation process gives rise to undesirable feature, then the criteria for natural selection will cease to ensure the chromosomes do not live to mate. Changing the position and sequence of binary code, a new set of frnf, srnf, trnf, $r c l, r c d$ can be generated by mutation process. For a better look into the mutation process, following are some of the illustrated examples. 
Mutation for first natural frequency

Parent one

\begin{tabular}{|l|l|l|l|l|l|l|l|l|l|}
\hline 1 & 1 & 0 & 1 & 0 & 1 & 0 & 1 & 0 & 1 \\
\hline
\end{tabular}

Mutated gene

\begin{tabular}{|l|l|l|l|l|l|l|l|l|l|}
\hline 1 & 1 & 1 & 0 & 1 & 1 & 0 & 1 & 1 & 0 \\
\hline
\end{tabular}

Mutation for second natural frequency

Parent one

\begin{tabular}{|l|l|l|l|l|l|l|l|l|l|}
\hline 1 & 0 & 1 & 1 & 0 & 1 & 0 & 1 & 0 & 1 \\
\hline
\end{tabular}

Mutated gene

\begin{tabular}{|l|l|l|l|l|l|l|l|l|l|}
\hline 0 & 1 & 1 & 0 & 1 & 0 & 1 & 1 & 1 & 0 \\
\hline
\end{tabular}

Mutation for third natural frequency

Parent one

\begin{tabular}{|l|l|l|l|l|l|l|l|l|l|}
\hline 1 & 1 & 0 & 1 & 1 & 1 & 0 & 1 & 1 & 0 \\
\hline
\end{tabular}

Mutated gene

\begin{tabular}{|l|l|l|l|l|l|l|l|l|l|}
\hline 0 & 0 & 1 & 1 & 1 & 0 & 1 & 1 & 0 & 1 \\
\hline
\end{tabular}

Figure 22. Mutation of genes for different natural frequencies.

Stage 5: Fittest offspring evaluation

The process for crossover and mutation result in the generation of new offspring with new genes and is evaluated for fittest child through optimization. The results from the data pool are compared with that of newly formed offspring out of crossover and the newly formed chromosomes out of mutation process lead to ensure the fittest offspring.

This process of evaluation for fittest offspring is computed using objective function. First three relative modal parameters like natural frequencies are considered as input parameters to the developed genetic algorithm model and two outputs parameters such as relative crack position, relative depth of crack are obtained. The flow chart for the proposed genetic model algorithm is as below. 


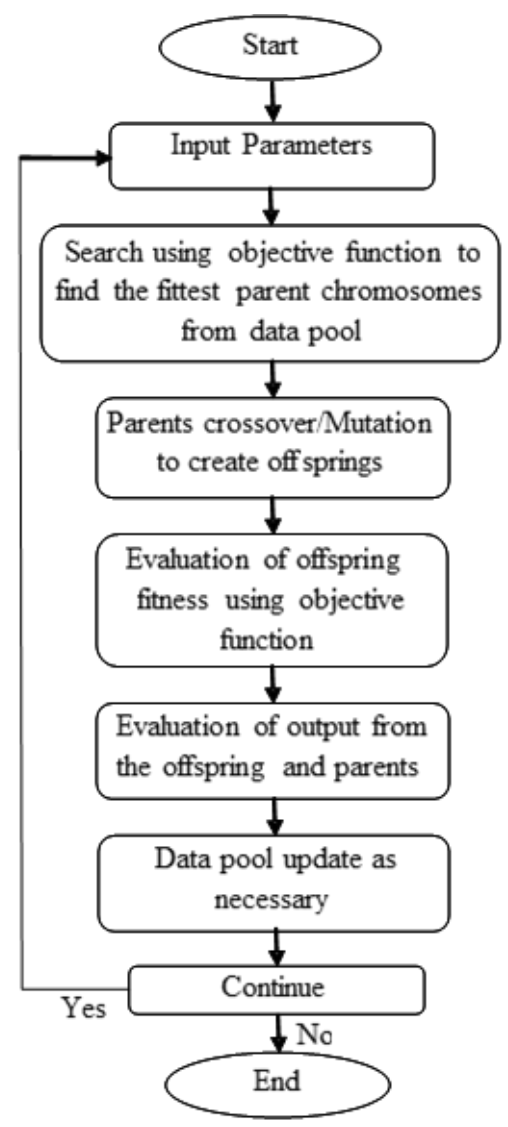

Figure 23. Flow chart for the proposed genetic algorithm.

Table 6. Comparison of results from GA model, numerical model and experimental model.

\begin{tabular}{|c|c|c|c|c|c|c|c|c|c|c|c|}
\hline \multirow{2}{*}{ 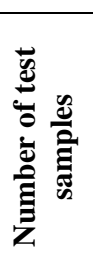 } & \multirow{2}{*}{ 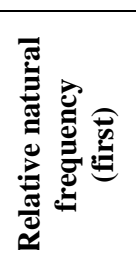 } & \multirow{2}{*}{ 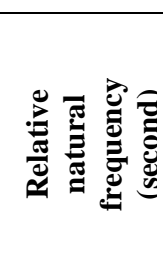 } & \multirow{2}{*}{ 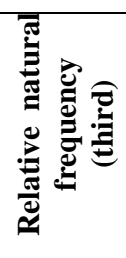 } & \multicolumn{2}{|c|}{ GA model } & \multicolumn{2}{|c|}{$\begin{array}{l}\text { Numerical } \\
\text { model }\end{array}$} & \multicolumn{2}{|c|}{$\begin{array}{c}\text { Experimental } \\
\text { model }\end{array}$} & \multicolumn{2}{|c|}{$\begin{array}{l}\text { \% deviation of } \\
\text { GA output from } \\
\text { experimental } \\
\text { result }\end{array}$} \\
\hline & & & & red & rcl & red & rcl & red & rcl & red & rel \\
\hline \multirow[t]{2}{*}{1} & 0.9818 & 0.9330 & 0.927 & 0.144 & 0.243 & 0.147 & 0.246 & 0.147 & 0.24 & 1.62 & 0.90 \\
\hline & 7 & 5 & 93 & 82 & 86 & 01 & 03 & 18 & & & \\
\hline \multirow[t]{2}{*}{2} & 0.9581 & 0.9331 & 0.927 & 0.145 & 0.344 & 0.145 & 0.347 & 0.145 & 0.34 & 1.59 & 1.02 \\
\hline & 8 & 1 & 32 & 01 & 43 & 07 & 89 & 29 & 796 & & \\
\hline \multirow[t]{2}{*}{3} & 0.9291 & 0.9480 & 0.927 & 0.244 & 0.446 & 0.246 & 0.448 & 0.247 & 0.44 & 0.96 & 0.48 \\
\hline & 3 & 3 & 18 & 69 & 83 & 87 & 89 & 06 & 901 & & \\
\hline \multirow[t]{2}{*}{4} & 0.9227 & 0.9439 & 0.924 & 0.342 & 0.542 & 0.343 & 0.542 & 0.343 & 0.54 & 0.29 & 0.17 \\
\hline & 8 & 1 & 81 & 91 & 16 & 79 & 88 & 91 & 311 & & \\
\hline \multirow[t]{2}{*}{5} & 0.9134 & 0.9366 & 0.916 & 0.543 & 0.544 & 0.548 & 0.544 & 0.548 & 0.54 & 0.80 & 0.67 \\
\hline & 4 & 7 & 66 & 97 & 91 & 11 & 07 & 33 & 858 & & \\
\hline
\end{tabular}




\section{DISCUSSION}

Some of the important related issues are to be taken into consideration for proper implementation of genetic algorithm for optimization of the solution. The decision of correct population size is a vital issue in proper implementation of Genetic algorithm technique. A population size limited to 30 is recommended as usual practice. A large population size consumes more computational time for diagnosis that may lead to poor performance and erratic results. Further improper selection of cross over rate may lead to early convergence. Higher cross over rates of the range between $85 \%$ to $90 \%$ are generally recommended to avoid premature convergence. Further a low mutation rate of $0.5 \%$ to $1 \%$ is a usually practice for optimized solution.

Mutation is considered as an artificial and forced methodology to change any numerical values of chromosomes. It is worth to avoid mutation process due to its random nature as it is likely to fall into local maxima and local minima. A small mutation rate is recommended to fulfil the convergence criteria. Decision of selection methodology also plays a vital role in proper selection of fittest chromosomes. In this current chapter, comparisons of output results from genetic algorithm, against experimental are presented in tabular form Table 6 . It may be noted that the percentage deviation of output results of GA model from experimental results do not exceed 3\%. Following deviation formulae have been used to calculate percentage deviation of experimental result from genetic algorithm model result.

Percentage of deviation in crack location $=$

$$
100 \times\left[\frac{\text { Experimental crack location }- \text { GA model based crack location }}{\text { Experimental crack location }}\right]
$$

Percentage of deviation in crack depth $=$

$$
100 \times\left[\frac{\text { Experimental crack depth }- \text { GA model based crack depth }}{\text { Experimental crack depth }}\right]
$$

Genetic algorithm is a powerful intelligent technique to solve optimisation problems with an appropriate selection of parameters and operators that can potentially explore the entire search space for closer solution and reach the global optimum. In the present work, a nonclassical optimization approach involving the various genetic algorithm parameters and operators has been proposed to localize cracked area of the damaged structure. Table 7 shows various genetic parameters and their magnitude used for optimization.

Table 7. Genetic parameters.

\begin{tabular}{cc}
\hline $\begin{array}{c}\text { Genetic evaluation } \\
\text { Parameters }\end{array}$ & $\begin{array}{c}\text { Type and magnitude } \\
\text { of parameters }\end{array}$ \\
\hline No. of generations & 150 \\
Size of population & 30 \\
Rate of crossover & 0.5 \\
Crossover type & Single point \\
Rate of mutation & 0.5 \\
Mutation type & Bit flip \\
\hline
\end{tabular}




\section{CONCLUSION}

The objective of the present research aims at establishing an effective technique to diagnose cracks in a damaged vibrating beam structure under a complex loading pattern. So a systematic study has been conducted to establish the influence of cracks on the modal characteristics of a damaged beam.

In the present work deviation in the output obtained using various techniques such as numerical and experimental and genetic algorithm have been compared to understand the individual performance of the technique for evaluation of the state of depth and location of the crack. It may be established here that a local flexibility is induced at the crack position and the crack depth change the structural integrity sensitive indicators like relative mode shapes and relative natural frequency. It may be noted here that the crack positions and the crack depths influence mode shapes and the natural frequency of a vibrating beam structure. In the present research, efforts have been made to locate the position of crack and its severity by adopting Genetic algorithm as an artificial intelligence technique. In such techniques relative natural frequencies obtained from experimental data are considered as input parameters to the Genetic algorithm.

Theoretical and numerical analysis establish the fact that the presence of crack influences the vibration parameters like natural frequencies and mode shapes. The natural frequency decreases as the crack locations shifts towards free ends of the beam. Further to state that the relative natural frequency drops with higher crack depths irrespective of crack locations. The output results obtained using genetic algorithm technique are compared with experimental results and the calculated values of deviation do not exceed $3 \%$ as evident from Table-6. For better accuracy, the sophisticated and more sensitive and advanced equipment can be put in place for the conduct of experiments. This will give more reliable output for condition monitoring of structures.

The application of genetic algorithm is more useful in the field where traditional methods are incapable to produce desired results. A noticeable change in the relative natural frequencies and relative mode shapes has been observed following a change in the crack locations and crack depths. Changes become more prominent in the relative natural frequencies at higher crack depths. A lower relative crack depth shows a little effect on its relative natural frequencies.

The whole study aims at developing an effective crack diagnostic tool for correct prediction of crack locations and crack depths in a cracked beam structure. The influence of crack on modal characteristics like natural frequencies and mode shapes have been studied successfully using the developed tool. A closer agreement in the experimental and genetic algorithm results for crack diagnosis ensures a way for automated condition monitoring of the damaged structures.

\section{REFERENCES}

[1] He Y, Guo D, Chu F. Using genetic algorithms and finite element methods to detect shaft crack for rotor-bearing system. Mathematics and computers in simulation. 2001;57(1-2):95-108.

[2] Hao H, Xia Y. Vibration-based damage detection of structures by genetic algorithm. Journal of computing in civil engineering. 2002;16(3):222-229.

[3] Krawczuk M. Application of spectral beam finite element with a crack and iterative 
search technique for damage detection. Finite Elements in Analysis and Design. 2002;38(6):537-548.

[4] He RS, Hwang SF. Damage detection by an adaptive real-parameter simulated annealing genetic algorithm. Computers \& Structures. 2006;84(31-32):2231-2243.

[5] Perera R, Torres R. Structural damage detection via modal data with genetic algorithms. Journal of Structural Engineering. 2006;132(9):1491-1501.

[6] Chen HG, Yan YJ, Chen WH, Jiang JS, Yu L, Wu ZY. Early damage detection in composite wingbox structures using Hilbert-Huang transform and genetic algorithm. Structural Health Monitoring. 2007;6(4):281-297.

[7] Panigrahi SK, Chakraverty S, Mishra BK. Vibration based damage detection in a uniform strength beam using genetic algorithm. Meccanica. 2009;44(6):697.

[8] Vakil-Baghmisheh MT, Peimani M, Sadeghi MH, Ettefagh MM. Crack detection in beam-like structures using genetic algorithms. Applied soft computing. 2008;8(2):1150-1160.

[9] Saridakis KM, Chasalevris AC, Papadopoulos CA, Dentsoras AJ. Applying neural networks, genetic algorithms and fuzzy logic for the identification of cracks in shafts by using coupled response measurements. Computers \& Structures. 2008;86(11-12):13181338.

[10] Meruane V, Heylen W. A hybrid real genetic algorithm to detect structural damage using modal properties. Mechanical Systems and Signal Processing. 2011;25(5):15591573.

[11] Nobahari M, Seyedpoor SM. Structural damage detection using an efficient correlationbased index and a modified genetic algorithm. Mathematical and Computer modelling. 2011;53(9-10):1798-1809.

[12] Buezas FS, Rosales MB, Filipich CP. Damage detection with genetic algorithms taking into account a crack contact model. Engineering Fracture Mechanics. 2011;78(4):695712.

[13] Zhang Y, Randall RB. Rolling element bearing fault diagnosis based on the combination of genetic algorithms and fast kurtogram. Mechanical Systems and Signal Processing. 2009;23(5):1509-1517.

[14] Agarwalla DK, Parhi DR. Effect of crack on modal parameters of a cantilever beam subjected to vibration. Procedia Engineering. 2013;51:665-669.

[15] Behera RK, Parhi DR, Sahu SK. Vibration analysis of a cracked rotor surrounded by viscous liquid. Journal of Vibration and Control. 2006;12(5):465-494.

[16] Das HC, Parhi DR. Online fuzzy logic crack detection of a cantilever beam. International Journal of Knowledge-based and Intelligent Engineering Systems. 2008;12(2):157-171.

[17] Dash AK, Parhi DR. Analysis of an intelligent hybrid system for fault diagnosis in cracked structure. Arabian Journal for Science and Engineering. 2014;39(2):1337-1357.

[18] Perera R, Ruiz A, Manzano C. Performance assessment of multicriteria damage identification genetic algorithms. Computers \& Structures. 2009;87(1-2):120-127.

[19] Friswell MI, Penny JE, Garvey SD. A combined genetic and eigensensitivity algorithm for the location of damage in structures. Computers \& Structures. 1998;69(5):547-556.

[20] Xiang J, Zhong Y, Chen X, He Z. Crack detection in a shaft by combination of wavelet-based elements and genetic algorithm. International Journal of Solids and Structures. 2008;45(17):4782-4795.

[21] Zhang L, Jack LB, Nandi AK. Fault detection using genetic programming. Mechanical Systems and Signal Processing. 2005;19(2):271-289.

[22] Singh SK, Tiwari R. Identification of a multi-crack in a shaft system using transverse 
frequency response functions. Mechanism and machine theory. 2010;45(12):18131827.

[23] Nguyen N, Lee H. Bearing fault diagnosis using adaptive network based fuzzy inference system. In: International Symposium on Electrical \& Electronics Engineering. Vietnam 2007;24-25.

[24] Jena PK, Thatoi DN, Nanda J, Parhi DR. Effect of damage parameters on vibration signatures of a cantilever beam. Procedia engineering. 2012;38:3318-3330.

[25] Parhi DR, Dash AK. Faults detection by finite element analysis of a multi cracked beam using vibration signatures. International Journal of Vehicle Noise and Vibration. 2010;6(1):40-54.

[26] Parhi DR, Kumar DA. Analysis of methodologies applied for diagnosis of fault in vibrating structures. International Journal of Vehicle Noise and Vibration. 2009;5(4):271-286.

[27] Parhi DR, Singh MK. Navigational strategies of mobile robots: a review. International Journal of Automation and Control. 2009;3(2-3):114-134.

[28] Pothal JK, Parhi DR. Navigation of multiple mobile robots in a highly clutter terrains using adaptive neuro-fuzzy inference system. Robotics and Autonomous Systems. 2015;72:48-58.

[29] Singh MK, Parhi DR. Path optimisation of a mobile robot using an artificial neural network controller. International Journal of Systems Science. 2011;42(1):107-120.

[30] Pawar PM, Ganguli R. Genetic fuzzy system for online structural health monitoring of composite helicopter rotor blades. Mechanical Systems and Signal Processing. 2007;21(5):2212-2236.

[31] Das HC, Parhi DR. Detection of the crack in cantilever structures using fuzzy gaussian inference technique. AIAA Journal. 2009;47(1):105-115.

[32] Das HC, Parhi DR. Application of neural network for fault diagnosis of cracked cantilever beam. In: World Congress on Nature \& Biologically Inspired Computing (NaBIC). 2009;1303-1308.

[33] Sahu S, Parhi DR. An inverse approach of damage detection of beam like structure using intelligent hybrid fuzzy rule base system. Perspective in science. 2016.

[34] Sahu S, Parhi DR. Performance comparison of genetic algorithm and differential evolution algorithm in the field of damage detection in crack structures. Journal of vibration engineering and technology. 2017;5(2).

[35] Deepak BBVL, Parhi DR. Control of an automated mobile manipulator using artificial immune system. Journal of Experimental \& Theoretical Artificial Intelligence. 2016;28(1-2):417-439.

[36] Mohanty PK, Parhi DR. A new intelligent motion planning for mobile robot navigation using multiple adaptive neuro-fuzzy inference system. Applied Mathematics \& Information Sciences. 2014;8(5):2527.

[37] Pham DT, Parhi DR. Navigation of multiple mobile robots using a neural network and a Petri Net model. Robotica. 2003;21(1):79-93.

[38] Pothal JK, Parhi DR. Navigation of multiple mobile robots in a highly clutter terrains using adaptive neuro-fuzzy inference system. Robotics and Autonomous Systems. 2015;72:48-58.

[39] Parhi DR, Behera AK. Dynamic deflection of a cracked shaft subjected to moving mass. Transactions of the Canadian Society for Mechanical Engineering. 1997;21(3):295-316.

[40] Jena PK, Thatoi DN, Nanda J, Parhi DRK. Effect of damage parameters on vibration signatures of a cantilever beam. Procedia engineering. 2012;38:3318-3330. 
[41] Behera RK, Pandey A, Parhi DR. Numerical and experimental verification of a method for prognosis of inclined edge crack in cantilever beam based on synthesis of mode shapes. Procedia Technology. 2014;14:67-74.

[42] Thatoi DN, Das HC, Parhi DR. Review of techniques for fault diagnosis in damaged structure and engineering system. Advances in Mechanical Engineering. 2012;4:327569.

[43] Parhi DR, Behera AK. Dynamic deflection of a cracked beam with moving mass. Proceedings of the Institution of Mechanical Engineers, Part C: Journal of Mechanical Engineering Science. 1997;211(1):77-87.

[44] Pandey A, Sonkar RK, Pandey KK, Parhi DR. Path planning navigation of mobile robot with obstacles avoidance using fuzzy logic controller. IEEE 8th International Conference on Intelligent Systems and Control: Green Challenges and Smart Solutions. 2014;36-41.

[45] Mohanty PK, Parhi DR. Cuckoo search algorithm for the mobile robot navigation, Lecture Notes in Computer Science (including subseries Lecture Notes in Artificial Intelligence and Lecture Notes in Bioinformatics). 2013;8297 LNCS (PART 1):527536.

[46] Singh MK, Parhi DR, Bhowmik S, Kashyap SK. Intelligent controller for mobile robot: Fuzzy logic approach. In: The 12th International Conference of International Association for Computer Methods and Advances in Geomechanics (IACMAG). 2008;3:1755-1762.

[47] Mohanty PK, Parhi DR. Optimal path planning for a mobile robot using cuckoo search algorithm. Journal of Experimental \& Theoretical Artificial Intelligence. 2016;28(12):35-52.

[48] Shaari MS, Ariffin AK, Takahashi A, Abdullah S, Kikuchi M, Akramin MRM. Fatigue crack growth analysis on square prismatic with embedded cracks under tension loading. Journal of Mechanical Engineering and Sciences. 2017;11(1):2511-2526.

[49] Lau KT, Ahsan Q, Shueb MI, Othman R. Vibrational damping behaviors of graphene nanoplatelets reinforced NR/EPDM nanocomposites. Journal of Mechanical Engineering and Sciences. 2017;11(4):3274-3287.

[50] Er-raoudi, M, Diany M, Aissaoui H, Mabrouki M. Gear fault detection using artificial neural networks with discrete wavelet transform and principal component analysis. Journal of Mechanical Engineering and Sciences. 2016;10(2):2006-2019.

[51] Tezara C, Siregar JP, Lim HY, Fauzi FA, Yazdi MH, Moey LK, Lim JW. Factors that affect the mechanical properties of kenaf fiber reinforced polymer: A review. Journal of Mechanical Engineering and Sciences. 2016;10(2):2159-2175.

[52] Yusof MFM, Kamaruzaman MA, Zubair M, Ishak M. Detection of defects on weld bead through the wavelet analysis of the acquired arc sound signal. Journal of Mechanical Engineering and Sciences. 2016;10(2):2031-2042.

[53] Fauzi F, Ghazalli Z, Siregar J. Effect of various kenaf fiber content on the mechanical properties of composites. Journal of Mechanical Engineering and Sciences. 2016;10:2226-33.

[54] Tada H, Paris PC, Irwin GR. The stress analysis of cracks. Handbook, Del Research Corporation. 1973. 